\title{
FISCALIDAD LOCAL Y SUBVENCION POR CAPITALIDAD. UN ANALISIS DE LA UNION INTERNACIONAL DE CIUDADES $Y$ PODERES LOCALES
}

$341.12: 336.2$

por

\section{Carlos-Enrique Ruiz del Castillo y de Navascués}

Secretario técnico del Centro de Cooperación Intermunicipal del Instituto de Estudios de Administración Local

La residencia del Gobierno o de la Jefatura del Estado en la capitalidad de una Nación, el establecimiento del aparato burocrático y administrativo $\mathrm{y}$, como consecuencia, la multiplicación de problemas relativos al uso del suelo (radicación de edificios, tráfico) y a la utilización de servicios, potenciando una congestión que de suyo tiene ya la importancia que abruma a una gran ciudad, es motivo de reflexión que preocupa a Alcaldes y gestores de este tipo de urbes.

Uno de los aspectos que la capitalidad estatal confiere a la ciudad que la soporta (y cualquiera de los sentidos de este verbo no es desdeñable en este caso) lo constituye la acreditación de las misiones extranjeras; y a este aspecto de la capitalidad se refieren también las líneas que siguen, relativas a la práctica internacional.

En efecto, en noviembre de 1978, la Unión Internacional de Ciudades y Poderes Locales remitió a las Uniones Nacionales miembros un cuestionario que dio lugar a una clasificación y análisis de las respuestas y que cabe expresar como sigue, según condensación que se debe a E. HaRlofr (1).

(1) Iula Nouvelles. La Haya, junio de 1979, vol. 13, núm. 6. 
He aquí la pregunta formulada a las Uniones Nacionales:

Las ciudades que tienen estatuto de capitalidad o que representan la sede del Gobierno, ireciben algún tipo de indemnización por parte de éste, en compensación del impuesto territorial del que se encuentran exentos los edificios propiedad de los gobiernos extranjeros (embajadas, cancillerias, residencias de los diplomáticos, etc.)? Si esto es así, ¿cómo está cifrada la compensación y qué otros aspectos pueden interesar a ciudades que están en situaciones parecidas?

Lógicamente, las respuestas recogidas contienen elementos variados y dispares. Así, de las once Uniones Nacionales que han atendido el cuestionario y de las fuentes propias de información de la Unión Internacional de Ciudades y Poderes Locales, cabe deducir un tratamiento variado del problema, no siempre sobre la base de una indemnización que el Gobierno asigna al Municipio de la capitalidad. En Londres, los impuestos inmobiliarios son sustituidos por una subvención particular. Bruselas recibe una asignación que le compensa de los gastos que experimenta como capital de la Nación. Bonn se beneficia de una compensación que le facilita el Gobierno nacional, por una parte, y los Estados federados, por otra, en atención a los gastos en que incurre como sede del Gobierno federal. Washington D.C. recibe una subvención especial que le compensa de las exenciones contributivas territoriales concedidas a los inmuebles del Gobierno federal.

Las respuestas emitidas, condensadas en sus detalles, son las que a continuación se exponen, siguiendo el orden alfabético de las Naciones cuya Unión Nacional miembro informa.

Naturalmente, dichas respuestas - que en todo caso entrañan el inconveniente de su condensación - tienen que ser interpretadas a la luz del contexto fiscal de cada país, atendidos en el respectivo sistema de ingresos públicos, tanto sus fuentes como su reparto entre los distintos escalones de la Administración, desde el central hasta el local, sin perder de vista las competencias que tienen distribuidas los planos superiores, intermedios y locales de esa Administración pública.

Los estudios que no hace mucho tiempo ha llevado a cabo el Centrọ Internacional para el Crédito Municipal, de La Haya (2),

(2) Economic and Financial Pictures of Cities in Western Europe, including Israel and Japan. C. I. C. C. La Haya, 1978. 
sobre las fuentes de ingresos de las Entidades locales de los países que han respondido a la encuesta, bien se trate de los Municipios en general, bien de las grandes ciudades en particular, dejaron ver que sólo Londres se nutre con fondos importantes procedentes de la imposición local, cifrados aproximadamente en la tercera parte del conjunto de sus ingresos y en la totalidad de los obtenidos de fuentes propias de financiación. Compárese esta situación con la de Washington D. C., que, aun siendo capital de un país en el que la fiscalidad territorial cubre casi el 85 por 100 de los ingresos locales, solamente nutre a través de esa fuente de ingresos una pequeña parte de sus fondos; los ingresos fundamentales provienen de una subvención del Gobierno federal por vía de compensación, aprobada por el Congreso, atendida la disminución de ingresos que deriva de las exenciones tributarias de que gozan las propiedades de ese Gobierno, muy numerosas en el Distrito, comparado con los demás Entes locales norteamericanos.

En la República Federal Alemana, Bonn obtiene sus ingresos principales mediante la tasa comercial sobre el capital y sobre el beneficio de las sociedades mercantiles, así como sobre los salarios que perciben sus empleados. Dicha tasa es compartida con el Gobierno federal y con los Estados federados, que absorben - uno y otros- el 40 por 100 de su rendimiento: Para compensar al Municipio por tal pérdida, el Gobierno federal atribuye a Bonn -y lo mismo hace con los demás Municipios- el 14 por 100 de sus ingresos procedentes de la imposición sobre la renta. De esta intercomunicación y reparto de tributos, queda un resultado neto para el Municipio alemán menos satisfactorio que en la situación anterior a este sistema fiscal. En este contexto, el párrafo 3 del artículo 11 del Decreto sobre asignación financiera hace que la ciudad de Bonn se beneficie, como mínimo, de la cantidad de 12 millones de Deutsche Marks (3) que le satisface el Estado de Renania del Norte y de Westfalia, en compensación por los gastos de carácter extraordinario o atípico que le ocasiona el ser sede de funciones federales. Hay que añadir a esa cantidad las aportaciones de los Estados federados.

En Austria, en 1978 Viena ha nutrido el 27 por 100 de sus ingresos con la asignación que tiene atribuida en virtud de la Ley de Perecuación Fiscal. La tributación local le aporta otro 32 por 100

(3) Unos 432 millones de pesetas al cambio actual de la divisa. 
de sus recursos, fundamentalmente por el rendimiento de la tasa sobre rentas y beneficios de las empresas mercantiles; un 27 por 100 por la recaudación del impuesto sobre salarios pagados por dichas empresas y un 14 por 100 por el producto del impuesto territorial. Las ciudades y Municipios austríacos que albergan delegaciones extranjeras y consulados no reciben ninguna indemnización por la pérdida que registran sus presupuestos por las exenciones fiscales concedidas a esos Entes extranjeros.

En Bélgica, el Fondo Municipal es la fuente más importante de ingresos para Bruselas desde 1977. Con independencia de esta atribución básica, existen otros fondos tanto para la capital como para los demás Municipios, pero su cuantía cede en importancia en favor de la participación en el Fondo Municipal. Bruselas recibe, además, una compensación por los gastos extraordinarios en que incurre por su condición de capitalidad.

Los Municipios de Dinamarca obtienen la mayor parte de sus ingresos mediante la tasa que grava las rentas particulares. Copenhague cuenta entre la fiscalidad local con una contribución territorial, pero su rendimiento no tiene demasiada importancia. Por otra parte, numerosos edificios de la capital, incluidas las viviendas construidas a partir de 1955, se hallan exentos de dicha contribución. Ningún Municipio de Dinamarca conoce ningún tipo de indemnización por la pérdida que soporta en virtud de las exenciones tributarias.

Ha quedado señalado más arriba el caso de la capital de los Estados Unidos. Dentro de esa estructura fiscal, Washington recibe una indemnización del Gobierno federal, a través del Distrito de Columbia, y en ella se tiene en cuenta la radicación de embajadas extranjeras, aunque es forzoso decir que la compensación carece de especial importancia.

La fiscalidad local en Finlandia confiere el mayor contingente de ingresos a los derivados de la tasa sobre las rentas particulares y sobre los beneficios de las sociedades. El 99 por 100 de los ingresos de la ciudad de Helsinki tiene dicha procedencia, y ni en ella ni en ningún otro Municipio finlandés existe imposición territorial. Por este concepto, pues, es irrelevante la radicación de misiones extranjeras o de edificios del Gobierno en Helsinki. Por otra parte, existen en Finlandia tasas públicas municipales que corresponde abonar a todo propietario de bienes raíces que se beneficia de los 
servicios de vialidad, alcantarillado y de cualquier otro tipo de equipamiento de utilidad pública. Entre esos propietarios, y en relación con la capitalidad, están incluidos los Gobiernos extranjeros, que quedan, pues, sujetos al pago de los servicios públicos de que se benefician.

Francia aplica las convenciones de Viena de 18 de abril de 1961 y de 24 de abril de 1963. En su virtud, París, que funciona como Municipio independiente, desde el punto de vista de su gestión, desde el 31 de diciembre de 1975, y que obtiene parte de sus ingresos -no muy importantes, ciertamente- a través de un gravamen total o parcial del valor en renta de las propiedades raíces, edificadas o sin edificar, no mantiene la fiscalidad sobre bienes, de otros gobiernos. En general, los inmuebles situados en territorio francés que pertenezcan a Estados extranjeros y que se encuentren afectados a la residencia oficial de sus misiones diplomáticas, gozan de exención permanente del impuesto territorial sobre edificaciones. Por otra parte, y si las condiciones de reciprocidad se mantienen, los embajadores y los demás agentes diplomáticos extranjeros no pueden ser gravados por el impuesto sobre la vivienda en el $\mathrm{Mu}$ nicipio de su residencia oficial.

Aludida ya la fiscalidad de Londres ocho párrafos más arriba, hay que señalar que en Gran Bretaña no están gravadas las propiedades de los Estados extranjeros. Sobre esta base, el Gobierno del Reino Unido atribuye una indemnización a las Entidades locales afectadas por la exención tributaria señalada. Dicha compensación es determinada con arreglo a una evaluación que practica un experto del Tesoro, que es inatacable por la vía jurídica. Queda entendido, para que ello pueda ser así, que el funcionario ha procedido a la valoración mediante la honrada comparación con propiedades equivalentes que circundan la extranjera exenta. Por otra parte, el Tesoro indemniza a las Entidades locales que han experimentado pérdidas por las exenciones fiscales del tipo analizado practicadas en su demarcación.

En Holanda, el 45 por 100 de los gastos de La Haya - sede del Gobierno- queda cubierto con ingresos procedentes del Fondo Municipal, otro 45 por 100 tiene su contrapartida en las subvenciones y el 10 por 100 restante es atendido con los rendimientos de la fiscalidad propia. Un 6 o un 7 por 100 de esta última es resultado de gravar la propiedad y el arrendamiento de los inmuebles. Pero 
La Haya sufre las consecuencias de las exenciones tributarias territoriales, ya que el Gobierno holandés con sede en la ciudad, como se ha dicho - la capital del Reino de los Países Bajos es Amsterdam-, no indemniza al Municipio por la pérdida de los ingresos que las exenciones tributarias indicadas introducen en su presupuesto.

Noruega tiene establecido para su Administración local un impuesto sobre las rentas de los particulares, como el practicado por Dinamarca y Finlandia y como ésta, también, grava los beneficios de las sociedades mercantiles. También como en Copenhague, Oslo tiene establecido un impuesto sobre la propiedad inmueble y su rendimiento no tiene sino una importancia muy relativa. Existen problemas relativos a la propiedad oficial extranjera, ya que el sistema fiscal beneficia con la exención a los inmuebles que sean propiedad de Estados extranjeros y el Municipio de Oslo no obtiene ningún tipo de compensación por la pérdida de ingresos que ello significa.

Suecia practica una fiscalidad local igual a la noruega, y tampoco el Poder central indemniza a los Municipios por la causa que nos ocupa. Vale recordar sin embargo, que, como en las otras Administraciones escandinavas, el rendimiento de la imposición territorial es de escasa entidad, de forma que el lucro cesante que deriva de las exenciones no reviste importancia.

Contrariamente a lo que sucede en Escandinavia, en los ingresos que la fiscalidad local aporta a las Administraciones suizas de este tipo, la partida fundamental no la constituye la imposición sobre ganancias y beneficios, aunque se trate de un renglón sustancioso. La Confederación Suiza no compensa a Berna por la pérdida de rendimientos fiscales debida a exenciones sobre los establecimientos del Gobierno central en la ciudad. Y tampoco por la originada por los privilegios fiscales de las embajadas y delegaciones extranjeras. Estos se mantienen por Suiza en la vertiente de la exención fiscal, en aplicación del artículo 23 de la Ley federal relativa a las convenciones de Viena de 1963.

En definitiva, cabe resumir, como lo hace E. HARLOFF, que si bien no es posible redactar una lista analógica de las tareas de las tareas de las capitales o de las sedes de Gobierno, bien se les pueden atribuir, además de la gestión de los servicios públicos tradicionales, las prestaciones que corresponden a toda gran ciudad y los cometidos que les corresponden por su función representativa. 
Los gastos crecientes que implica la prestación de los servicios tradicionales, su ampliación, la puesta en marcha de nuevas prestaciones y la inflación - como preocupación máxima de esta hora europea- han producido como consecuencia directa un incremento más rápido de los gastos en las Entidades locales que en los demás sectores públicos. Es lícito suponer que esta tendencia general en Europa corresponde a una situación pareja en otras Regiones del mundo. De hecho, la tasa de incremento de los gastos de las Entidades locales y regionales es superior, en la mayor parte de las Naciones, a la del aumento de los gastos públicos en general. Así lo desprende E. HaRLoff de un estudio llevado a cabo recientemente por el Consejo de Europa (4).

Pero, a la vez, las fuentes de recursos crecen a un ritmo menor. Así, las grandes ciudades se encuentran enfrentadas con un creciente foso entre sus ingresos y sus gastos. Ante esta realidad tienen que reducir sus servicios, funcionar con déficit, aumentar el rendimiento de sus actuales recursos o crear nuevos impuestos. En cualquier caso, se hallan situadas frente a las limitaciones derivadas de la incompetencia política, de las limitaciones legales del endeudamiento local, de la limitación de los tipos impositivos o del rendimiento total de la imposición y de las demás fuentes de ingresos. En general, la Administración local carece de los instrumentos fiscales más lucrativos. $Y$ hay que pensar que si una gran ciudad es además una capital o la sede de un Gobierno, se ve en la situación obligada de afrontar gastos todavía mayores.

Uno de los medios de proveer a esos gastos concretos fue examinado en la pequeña encuesta a que estas líneas se refieren, aunque sólo se tratara de posibilidades parciales. $\mathrm{Y}$ las respuestas han mostrado que en las situaciones en que los tipos de impuesto aportaban a las arcas locales ingresos nada desdeñables, aparecían compensadas las pérdidas que representaban las exenciones tributarias. No hay que decir que, por otra parte, existen o pueden existir otros métodos para incrementar los ingresos, tales como fuentes de rentas progresivas y elásticas, subvenciones especiales, compensaciones $o$ indemnizaciones por gastos extraordinarios (desde el punto de vista de las corporaciones municipales, y a este respecto,

(4) Les structures financières des collectivités locales et régionales en Europe. Répartition et péréquation financières, vol. II. Colección «Communes et Régions d'Europe», núm. 13. Consejo de Europa. Estrasburgo, 1976, pág. 72. 
la situación de aquéllas será tanto más cómoda cuanto menores sean las limitaciones a su libertad de movimientos, en función de la atribución de fondos para una gestión holgada). La mejor solución depende del sistema de rentas del país de que se trate y del reconocimiento por parte del Poder central del carácter extraordinario y con frecuencia exclusivo y peculiar de ciertos gastos que soportan, sin buscarlos, las ciudades con capitalidad. 
REVISTA

DE

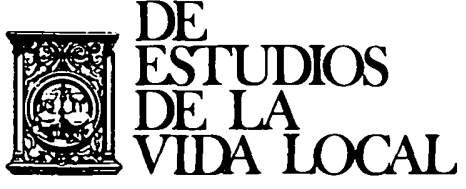

\section{ESTADISTICA ,}


REVL-1979, núm. 203. RUIZ DEL CASTILLO Y DE NAVASCUES, CARLOS-ENRIQUE. FISCALIDA...

REVL-1979, núm. 203. RUIZ DEL CASTILLO Y DE NAVASCUES, CARLOS-ENRIQUE. FISCALIDA... 